\title{
Transient pluripotent cell populations during primitive ectoderm formation: correlation of in vivo and in vitro pluripotent cell development.
}

\author{
T. A. Pelton ${ }^{\star}$, S. Sharma ${ }^{\star} \neq$, T. C. Schulz ${ }^{\star}$, , J. Rathjen and P. D. Rathjen \\ Department of Molecular Biosciences, University of Adelaide, Adelaide 5005, South Australia \\ ${ }^{*}$ Contributed equally to this work \\ ₹Current address: Department of Ophthalmology, Flinders University of South Australia, Bedford Park, SA 5042, Australia \\ §Current address: Laboratory of Cellular and Developmental Biology, Section of Mammalian Development, NIDDK, NIH, Bethesda, MD 50892, USA \\ IAuthor for correspondence (e-mail: peter.rathjen@adelaide.edu.au) \\ Accepted 24 September 2001 \\ Journal of Cell Science 115, 329-339 (2002) (C) The Company of Biologists Ltd
}

\section{Summary}

Formation and differentiation of a pluripotent cell population is central to mammalian development, and the isolation, identification and manipulation of human pluripotent cells is predicted to be of therapeutic use. Within the early mammalian embryo, two distinct populations of pluripotent cells have been described: the inner cell mass (ICM), which differentiates to form a second pluripotent cell populations, the primitive ectoderm. Indirect evidence suggests the existence of temporally distinct intermediate pluripotent cell populations as primitive ectoderm is formed. We coupled an in vitro model of primitive ectoderm formation (the transition of embryonic stem cells to early primitive ectoderm-like (EPL) cells) with ddPCR-based techniques to identify three novel genes, Psc1, CRTR-1 and PRCE, that were expressed differently during pluripotent cell progression. Detailed mapping of these genes with Oct4, RexI and Fgf5 on pregastrulation embryos provided the first molecular evidence for the existence of successive, temporally distinct pluripotent cell populations in the embryo between the ICM and primitive ectoderm. No evidence was found for spatial heterogeneity within the $\mathrm{Oct}^{+}$pool. The transition between populations correlated with morphological or developmental alterations in pluripotent cells in vivo. Genes that are temporally expressed during pluripotent cell progression may provide an opportunity for molecular discrimination of pluripotent cells at different stages of maturation in vivo and an understanding of the cellular origins and properties of pluripotent cell lines isolated from diverse sources. Furthermore, the strong correlation of gene expression demonstrated between EPL cell formation in vitro and primitive ectoderm formation in vivo validates EPL cells as a model for primitive ectoderm, thereby providing a model system for the investigation of pluripotent differentiation and an opportunity for directed differentiation of pluripotent cells to therapeutically useful cell populations.

Key words: Pluripotent, ES cells, EPL cells, ICM, Primitive ectoderm, Mammalian development, Psc1, CRTR-1, PRCE, Differential gene expression

\section{Introduction}

The development of many metazoans is programmed from fertilization by maternal determinants in the oocyte. As a consequence, the developmental fate of cells derived from early embryonic divisions is restricted according to their position in the embryo. By contrast, maternal instruction appears to play a substantially lesser role in the mammal, in which early development results in the formation of a population of pluripotent cells that are not markedly restricted in developmental potential and retain the ability to give rise to all embryonic and adult cell types (Smith, 1992).

The first differentiation event of mouse embryogenesis entails the elaboration of extra-embryonic lineages by formation of trophectoderm from outer cells of the embryo. Inner cells, which retain pluripotent differentiation capability, form the inner cell mass (ICM) of the blastocyst. At $\sim 4$ days post coitum (d.p.c.), ICM cells lining the blastocoelic cavity differentiate into primitive endoderm, the precursor of extraembryonic lineages including visceral and parietal endoderm.
Following this differentiation, pluripotent cells within the mouse embryo are referred to generically as the 'epiblast'. At around the time of implantation (4.5 d.p.c.), ICM cells commence a complex developmental program resulting in the formation of a second pluripotent cell population, the primitive ectoderm. Rapid proliferation, in which cell cycles as short as 5 hours have been reported (Snow, 1977), results in expansion of the pluripotent cell population from $\sim 25$ cells at 4.5 d.p.c. to 660 cells by 6.5 d.p.c. (Snow, 1977). Transplantation experiments (Beddington, 1983a) reveal alteration in the developmental potential of pre- and post-implantation pluripotent cells, and this is accompanied by alterations in gene expression (Haub and Goldfarb, 1991; Hebert et al., 1991; Rogers et al., 1991). Formation of the proamniotic cavity within the epiblast, apparently as a result of cell apoptosis (Coucouvanis and Martin, 1995), is accompanied by reorganization of the pluripotent cells into a pseudostratified epithelial monolayer. The primitive ectoderm that results from these cellular events comprises several thousand pluripotent 
cells by 7.0 d.p.c. that are unspecified until at least $6.0-6.5$ d.p.c. (Snow, 1977; Beddington, 1981; Beddington, 1982; Beddington, 1983b; Lawson et al., 1991) and which, during gastrulation, give rise to the three germ layers of the mammalian embryo.

Pluripotent cells are receiving considerable attention owing to the recognition that manipulation of pluripotent cell lines in vitro might provide a route to therapeutic cell production (Rathjen et al., 1998; Smith, 1998). Pluripotent cell lines with different cellular origins have been reported. Of these, mouse embryonic stem (ES) cells are stable lines that share many properties with ICM/early epiblast cells, including the ability to differentiate into all embryonic cell types including the germ line (Evans and Kaufman, 1981; Martin, 1981; Rathjen et al., 1999). Pluripotent embryonal carcinoma (EC) lines have been derived from human and mouse teratocarcinomas (Pera et al., 1990) and have diverse properties that may be explained by their different cellular origins and extended deregulated growth in vitro and in vivo. Pluripotent embryonic germ (EG) cell lines of mouse and human origin are derived by the reversion of primordial germ cells in vitro and share many properties with mouse ES cells (Resnick et al., 1992; Matsui et al., 1992; Shamblott et al., 1998). Finally, human ES cells, which are of considerable therapeutic potential, appear to be substantially equivalent but in several respects distinct from mouse ES cells (Thomson et al., 1998; Reubinoff et al., 2000). The cellular origin and identity of pluripotent cell lines are likely to affect their growth and differentiation characteristics in vitro. Recognition of pluripotent cell lines in vitro, identification of their closest embryological equivalents and investigation of their interrelationships within and across species is therefore of considerable importance. One approach is the identification of genes that are differently expressed within distinct pluripotent cell populations in vivo.

Although pluripotent cells are fundamental to mammalian embryogenesis, relatively little is known of the developmental behaviour or molecular profile of these cells. Several lines of evidence, including cell potency studies and the phenotypes of mutant embryos, suggest that progression from ICM to primitive ectoderm entails the progressive formation of temporally distinct pluripotent cell populations (Pelton et al., 1998). However, molecular characterization of these postulated populations has not been possible because few markers delineating this time in embryogenesis have been described. Of the reported proteins, the POU domain transcription factor Oct4 can be used to recognize all pluripotent cell populations (Rosner et al., 1990; Scholer et al., 1990), but only the Fgf5 (Haub and Goldfarb, 1991; Hebert et al., 1991), Rexl (Rogers et al., 1991) and Gbx2 (Chapman et al., 1997) genes are expressed differently in the ICM and primitive ectoderm. Moreover, the temporal expression of these genes in the pluripotent cell pool in vivo has only been crudely assessed.

We have previously described an in vitro culture system that results in lineage specific differentiation of mouse ES cells to a second pluripotent cell population termed early primitive ectoderm-like (EPL) cells (Rathjen et al., 1999; Lake et al., 2000). Analysis of gene expression markers, morphology, cytokine responsiveness and differentiation potential in vivo and in vitro suggests that EPL cells are most closely related to cells of the embryonic primitive ectoderm. As a progressive event, which occupies several days in vitro, the ES-EPL cell conversion can be used to model the differentiation of ICM to primitive ectoderm in vivo and provides a system for the identification of differently expressed genes within pluripotent cell populations of the ICM and primitive ectoderm. In contrast to embryonic tissue, starting material is not limited, whereas the homogeneity and relative synchrony of the cell transition minimize difficulties associated with culture heterogeneity, including persistence of undifferentiated ES cell 'nests', during spontaneous ES cell differentiation in vitro (Rathjen et al., 1990). Genes with temporally regulated expression during differentiation of the ICM to primitive ectoderm in vivo potentially provide a route to molecular identification of transient pluripotent cell populations in the embryo and their cellular equivalents in vitro. Furthermore, these genes would enable detailed mapping of the ES-EPL cell transition in vitro onto embryonic cell populations.

In this work, we used conventional differential display PCR (ddPCR) (Liang and Pardee, 1992) and modified ddPCR (internal display PCR (idPCR)) techniques to identify three novel genes that are expressed differently in ES and EPL cells: Periimplantation Stem Cell 1 (Psc1), Cp2-Related Transcriptional Repressor-1 (CRTR-1) and Protein Related to Cutl/ESP1 (PRCE). Detailed expression mapping of these genes and the reported markers Fgf5 and Rexl in vitro and in vivo revealed that expression of each gene was restricted to a temporally distinct subpopulation of pluripotent cells within the $\mathrm{Oct}_{4}{ }^{+}$pool. There was a correlation between expression of these genes in vitro and in vivo, and between alterations in gene expression and key developmental events in vivo. Characterization of these genes provides direct molecular evidence for the identification of EPL cells as like primitive ectoderm, supports the ES-EPL cell transition as a model for ICM to primitive ectoderm development in vivo and confirms the formation of temporally distinct pluripotent cell populations as the ICM differentiates to form primitive ectoderm both in the embryo and in vitro.

\section{Materials and Methods}

\section{Cell culture conditions and embryo collection}

ES and EPL cell culture were carried out as described by Rathjen et al. (Rathjen et al., 1999). D3 (Doetschman et al., 1985) and MBL5 (Pease et al., 1990) ES cell lines were obtained from L. Williams (Ludwig Institute, Melbourne).

Embryos used for in situ hybridization were obtained from timemated Swiss females. Mice were maintained on a 12 hour light/12 hour dark cycle and supplied with food and water ad libitum. Embryo stages are represented as d.p.c., assuming that fertilization occurred at the midnight preceding the discovery of the vaginal plug. Isolation and dissection of pre-implantation and post-implantation embryos were carried out according to Hogan et al. (Hogan et al., 1994) in dissection buffer (80\% ES Dulbecco's Modified Eagle's Medium (DMEM) (Gibco/BRL), 20\% foetal calf serum (FCS) (Commonwealth Serum Laboratories), $10 \mathrm{mM}$ HEPES pH 7.4), except that 5.0-5.5 d.p.c. embryos were removed from individual implantation sites by sectioning the uterus along the mesometrial side of the implantation site, prising open the decidua and shelling out the embryo with sharpened watchmakers forceps.

\section{Differential display PCR (ddPCR)}

Cytoplasmic RNA was isolated using the method of Edwards et al. (Edwards et al., 1985) from MBL5 (Psc1) or D3 (CRTR1, PRCE) ES 
cells and derivative EPL cells. EPL cells were formed and cultured for 2, 4 and 6 days in medium supplemented with 50\% MEDII or 50\% MEDII and 1000 units $\mathrm{ml}^{-1}$ LIF (Rathjen et al., 1999). EPL cells were passaged every two days. All pluripotent cells were cultured in gelatine-treated tissue-culture-grade plastic ware in the absence of feeders.

For ddPCR (Liang and Pardee, 1992) and idPCR, $2 \mu \mathrm{g}$ total RNA was denatured at $65^{\circ} \mathrm{C}$ for 10 minutes and added to a $25 \mu \mathrm{l}$ reverse transcription reaction mix containing $50 \mathrm{mM}$ Tris- $\mathrm{HCl} \mathrm{pH} 8.5,6 \mathrm{mM}$ $\mathrm{MgCl}_{2}, 40 \mathrm{mM} \mathrm{KCl}, 1 \mathrm{mM}$ DTT, $1.5 \mathrm{mM}$ each dNTP, $40 \mathrm{U}$ RNasin and $15 \mathrm{U}$ AMV reverse transcriptase. The ddPCR and idPCR reverse transcription reactions were primed with $100 \mathrm{ng} 3^{\prime}$ anchored-oligo d(T) primer (5'-ATGAATTCTTTTTTTTTTTTA/C/GN-3') or $250 \mathrm{ng}$ of 3' -hp primer (5'-TAGAATTCCGTNCGTAGTTCTTGAGAACCA$3^{\prime}$ ) (N represents A, C, G or T), respectively, and incubated for 1 hour at $42^{\circ} \mathrm{C}$ or $50^{\circ} \mathrm{C}$ respectively followed by incubation at $94^{\circ} \mathrm{C}$ for 5 minutes.

1-2 $\mu \mathrm{l}$ of cDNA was used as template in $25 \mu \mathrm{l}$ PCR reactions containing $1.5 \mathrm{mM} \mathrm{MgCl}_{2}, 1 \times$ Taq buffer (Geneworks), $20 \mu \mathrm{M}$ each dNTP, $37.5 \mathrm{ng}$ arbitrary tenmer (Operon technologies), $5 \mu \mathrm{Ci}\left[\alpha-{ }^{33} \mathrm{P}\right]$ dATP, $1 \mathrm{U}$ Taq polymerase (Geneworks) and $100 \mathrm{ng}$ of 3 '-anchoredoligo d(T) primer (ddPCR) or $500 \mathrm{ng} 3^{\prime}$-hp (idPCR). PCR reactions were amplified in a MJ Research PTC-100 thermal cycler for 40 cycles of $94^{\circ} \mathrm{C}$ for 1 minute, $42^{\circ} \mathrm{C}$ for 1 minute, $72^{\circ} \mathrm{C}$ for 30 seconds (ddPCR) or 40 cycles of $94^{\circ} \mathrm{C}$ for 30 seconds, $42^{\circ} \mathrm{C}$ for 30 seconds, $72^{\circ} \mathrm{C}$ for 30 seconds (idPCR), followed by a final extension at $72^{\circ} \mathrm{C}$ for 5 minutes. PCR products were separated by electrophoresis on $6 \%$ denaturing polyacrylamide gels and exposed to X-ray film for 1-3 days.

Selected PCR products were excised from the gel and eluted in 100 $\mu \mathrm{l}$ of $0.5 \mathrm{M}$ ammonium acetate, $10 \mathrm{mM}$ magnesium acetate, $1 \mathrm{mM}$ EDTA pH 8.0, $0.1 \%$ SDS at $50^{\circ} \mathrm{C}$ for 5-20 hours. $1 \mu 1$ of eluted ddPCR product was used directly as a template in $100 \mu \mathrm{l}$ PCR reamplification reactions under the same conditions as the original ddPCR or idPCR, omitting radioactive label. Reamplified PCR products were cloned into pBluescript $\mathrm{KS}$ and sequenced using $\mathrm{T} 7$ and $\mathrm{T} 3$ primers, using a T7 DNA sequencing kit (Pharmacia).

Use of the more complex reverse transcription primer for idPCR decreased the number of products amplified with each primer combination but reduced the background of spurious amplification products thereby facilitating reamplification and cloning of specific differently expressed products.

\section{RNA isolation and northern blot analysis}

Cytoplasmic RNA was isolated from cultured cells using the method of Edwards et al. (Edwards et al., 1985). Poly-A ${ }^{+}$RNA was isolated using the method of Celano et al. (Celano et al., 1993). Northern blot analysis was carried out as described in Thomas et al. (Thomas et al., $1995)$ using $25 \mu \mathrm{g}$ total RNA or $4 \mu \mathrm{g}$ poly- $\mathrm{A}^{+}$RNA. DNA probes were prepared from DNA fragments using a Gigaprime labelling kit (Geneworks). Fragments for CRTR-1 (736 bp), Pscl (458bp) and $P R C E$ (232 bp) were excised from pBluescript KS II clones by XhoIBamHI, BamHI-HindIII and BamHI-HindIII digestion, respectively. Rexl, Fgf5, Oct4 and $m G A P$ probes were as described in Rathjen et al. (Rathjen et al., 1999). Band intensity was determined by volume integration using ImageQuant (Molecular Dynamics)

\section{In situ hybridization}

Wholemount in situ hybridization of both cell layers and embryos was carried out using the method of Rosen and Beddington (Rosen and Beddington, 1993) with the following modifications. Cell layers and 3.5-5.5 d.p.c. embryos were washed in RIPA buffer three times for 20 minutes before post-fixing. Embryos were prehybridized, hybridized and washed at $63.5^{\circ} \mathrm{C}$ for $P s c 1,65^{\circ} \mathrm{C}$ for Oct4, Rexl, CRTR- 1 and $P R C E$ and $68^{\circ} \mathrm{C}$ for $F g f 5$. The conjugate of anti-digoxygenin Fab with alkaline phosphatase was not preabsorbed with embryo powder prior to use in cell layer in situ hybridization. Sense and antisense CRTR1 digoxygenin riboprobes were generated from the pBluescript II KS

A

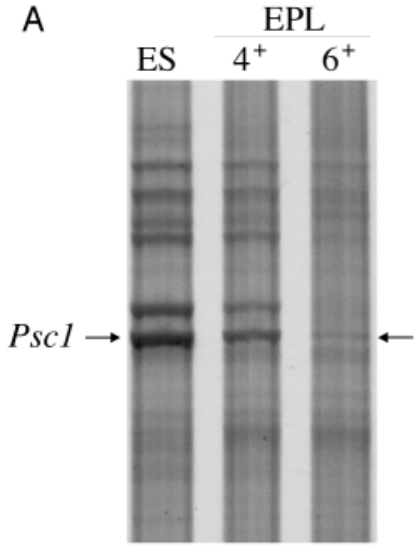

B

EPL

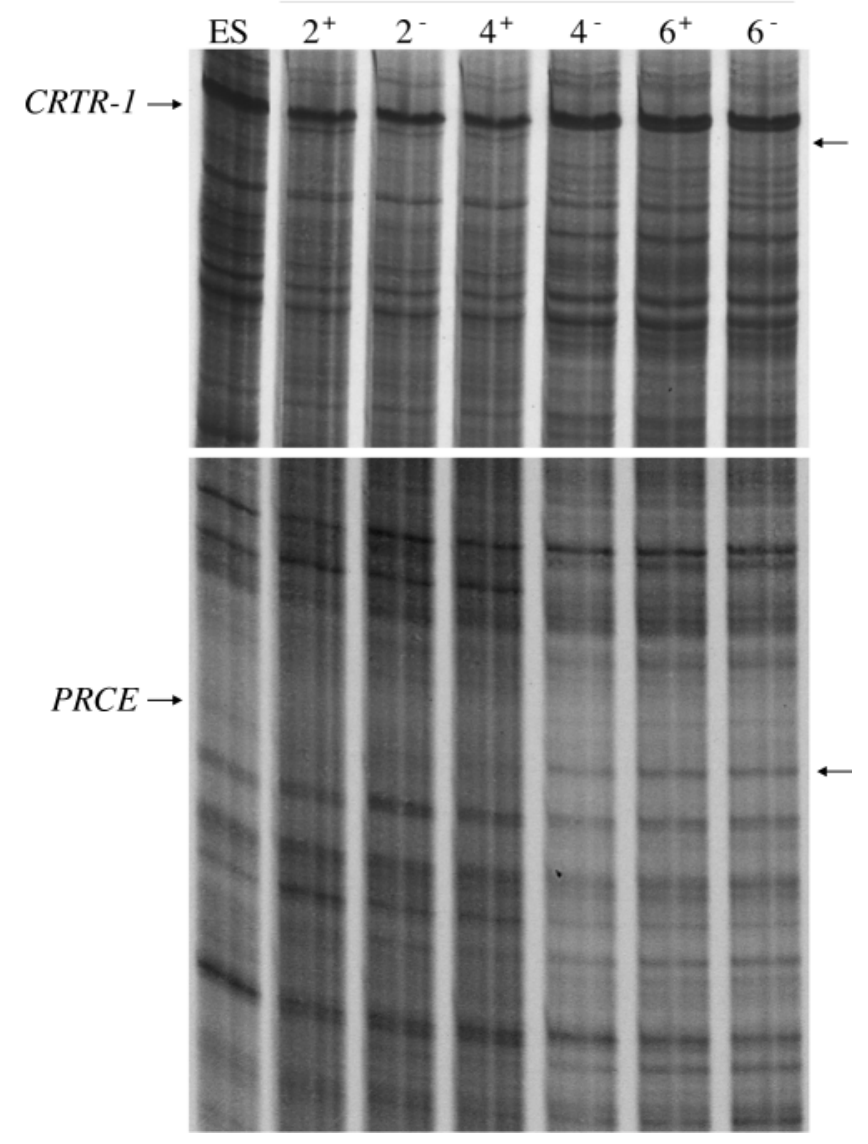

Fig. 1. IdPCR and ddPCR analysis of ES and EPL cell RNA. (A) Cytoplasmic RNA was isolated from ES cells and EPL cells grown for 4 or 6 days in the presence of $50 \%$ MEDII + LIF (+). Then, $2 \mu \mathrm{g}$ of this RNA were analysed by idPCR using the $5^{\prime}$ primer OPB-04 (GGACTGGAGT; Operon Technologies). PCR products were resolved by electrophoresis on a $6 \%(\mathrm{v} / \mathrm{v})$ denaturing polyacrylamide gel. (B) Cytoplasmic RNA was isolated from ES cells and EPL cells grown for 2, 4 or 6 days in 50\% MEDII in the presence $(+)$ or absence (-) of LIF. Then, $2 \mu \mathrm{g}$ of this RNA were analysed by ddPCR using the $5^{\prime}$ primer OPA-01 (CAGGCCCTTC; Operon Technologies) PCR products were resolved by electrophoresis on a $6 \%(\mathrm{v} / \mathrm{v})$ denaturing polyacrylamide gel. Arrows mark the indicated products. 

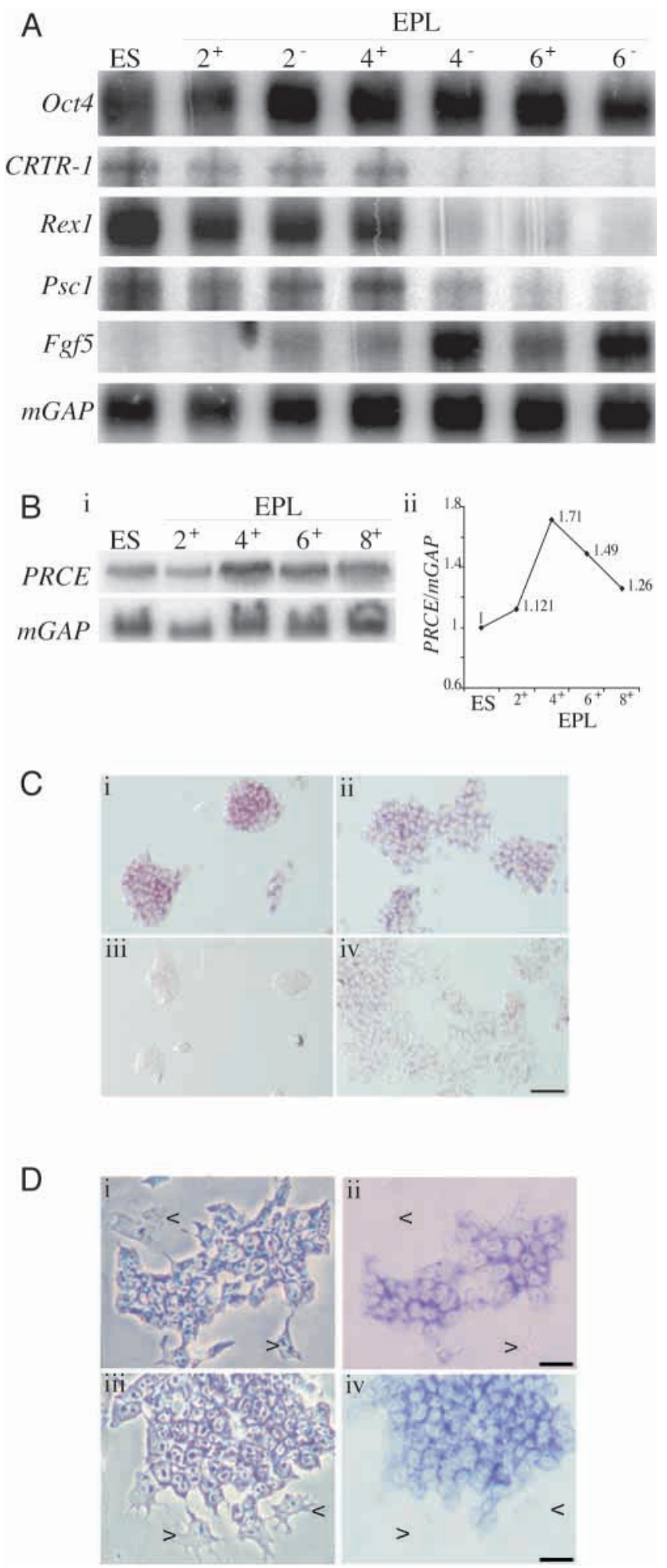

clone by BamHI digestion and transcription with T7 RNA polymerase, and by XhoI digestion and transcription with T3 RNA polymerase, respectively. Sense and antisense Pscl digoxygeninlabelled-riboprobes were generated from the pBluescript II KS clone by digestion with HindIII and BamHI, respectively, and transcription with T3 and T7 RNA polymerase, respectively. PRCE sense and antisense digoxygenin riboprobes were generated from the pBluescript KS II clone by BamHI digestion and transcription with
Fig. 2. Expression of cloned PCR products in pluripotent cells. (A) Northern blot analysis of $4 \mu \mathrm{g}$ poly- $\mathrm{A}^{+} \mathrm{RNA}$, isolated from ES cells and EPL cells grown for 2, 4 or 6 days in 50\% MEDII in the presence (+) or absence (-) of LIF, probed for Oct4, CRTR1, Rex1, $P s c 1, F g f 5$ and $m G A P$. Transcript sizes were: Oct4, $1.6 \mathrm{~kb}$; CRTR1, $9.4 \mathrm{~kb} ; \operatorname{Rexl}, 1.9 \mathrm{~kb} ; P s c 1,5.5 \mathrm{~kb} ; F g f 5,2.7 \mathrm{~kb}$; and $m G A P, 1.5$ kb. (Bi) Northern blot analysis of $25 \mu \mathrm{g}$ total RNA isolated from ES cells and EPL cells grown for 2, 4, 6 or 8 days in 50\% MEDII in the presence of LIF (+) and probed for PRCE and $m G A P$ expression. Transcript sizes were: PRCE, $6.6 \mathrm{~kb} ; m G A P, 1.5 \mathrm{~kb}$. (Bii) Quantitation of northern in (Bi). PRCE expression was normalized against the $m G A P$ loading control and expressed as a ratio, with ES cells assigned a value of 1. (C) In situ hybridization of ES cells (i, iii) and EPL cells cultured for 2 days in the presence of MEDII + LIF (ii, iv) with Oct4 (i, ii) and PRCE (iii,iv) antisense digoxygenin-labelled riboprobes. Images were captured using Hoffmann interference contrast microscopy. Bar, $90 \mu \mathrm{m}$. (D) In situ hybridization of EPL cells cultured for 4 days in the presence of MEDII and LIF with CRTR-1 (i, ii) and PRCE (iii, iv) antisense digoxygenin-labelled riboprobes. (i, iii) Phase contrast microscopy; (ii, iv) bright field microscopy. Arrows denote differentiated cells. Bar, $25 \mu \mathrm{m}$. Equivalent cell populations to those illustrated in $\mathrm{C}$ and $\mathrm{D}$ were probed with digoxygenin-labelled sense probes and failed to develop colour (data not shown).

T3 RNA polymerase, and by HindIII digestion and transcription with T7 RNA polymerase, respectively. Rexl sense and antisense probes were produced from an 848 bp clone in pCR ${ }^{\mathrm{TM}} \mathrm{II}$ (Hosler et al., 1989) (obtained from N. Clarke) by digestion with BamHI and XbaI, respectively, and transcription with T7 and Sp6 RNA polymerases, respectively. Oct4 and Fgf5 probes were generated as described in Rathjen et al. (Rathjen et al., 1999).

\section{Results}

Identification of genes expressed differently in ES and EPL cells

Conventional ddPCR and idPCR (T. C. Schulz, PhD thesis, Adelaide Univeristy, 1996; see Materials and Methods) were used to investigate temporal changes in gene expression associated with the ES-EPL cell transition. ES cells were compared with EPL cells maintained in culture for 2, 4 and 6 days in medium containing 50\% MEDII in the presence and absence of LIF (Fig. 1). LIF has been previously shown to retard the formation of primitive ectoderm in embryoid bodies and EPL cells in culture (Shen and Leder, 1992; Rathjen et al., 1999). The expression profiles of three differently expressed products that were selected for further analysis are indicated in Fig. 1. Pscl was expressed in ES cells and EPL cells cultured for 4 days in the presence of 50\% MEDII + LIF and was downregulated in EPL cells cultured in 50\% MEDII + LIF for 6 days (Fig. 1A). CRTR- 1 was expressed in EPL cells cultured for 2 and 4 days in the presence or 2 days in the absence of LIF, and was downregulated in EPL cells with further culture in MEDII or MEDII + LIF (Fig. 1B). PRCE was expressed at low levels in ES cells and EPL cells cultured for 2 days in 50\% MEDII or 2 and 4 days in 50\% MEDII + LIF, and was upregulated in EPL cells cultured for 4 and 6 days in 50\% MEDII or 6 days in 50\% MEDII + LIF (Fig. 1B).

\section{Expression and validation of cloned ddPCR transcripts \\ Differently expressed bands corresponding to CRTR1, Pscl}


A

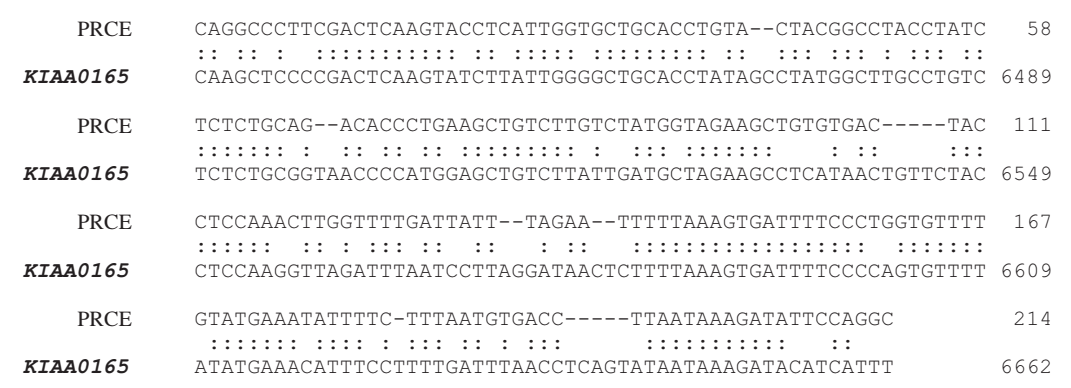

B

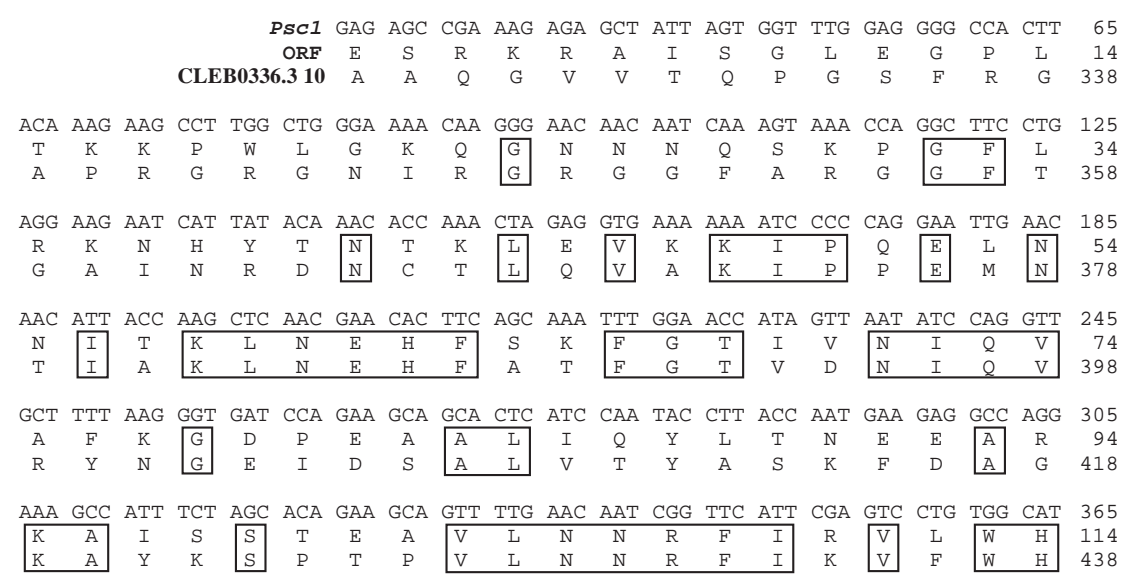

AGA GAG AAC AAT GAG CAA CCA

$\begin{array}{lllllll}R & E & N & N & E & Q & P\end{array}$
Fig. 3. Sequence and analysis of $P R C E$ and $P s C l$. (A) Alignment of the $P R C E$ ddPCR product sequence with the KIAA0165 cDNA sequence. (B) Alignment of the Pscl idPCR product nucleotide sequence and open reading frame (ORF) with the predicted $C$. elegans ORF CELB0336.3.

and PRCE were excised from gels and cloned into pBluescript. Correct isolation and cloning of differently expressed cDNA fragments was confirmed by northern blot analysis. In contrast to ddPCR-based techniques, which may not be quantitative owing to competition between transcripts for primer binding, this provides a definitive and quantitative indication of transcript expression.

Poly- $\mathrm{A}^{+} \mathrm{RNA}$, isolated from ES and EPL cells cultured in $50 \%$ MEDII in the presence or absence of exogenous LIF for 2, 4 and 6 days was analysed by northern blot for expression of Oct4, CRTR-1, Rexl, Fgf5 and Pscl (Fig. 2A). PRCE expression was confirmed by northern blot of total RNA from ES and EPL cells after 2, 4, 6 and 8 days of culture in $50 \%$ MEDII in the presence of LIF (Fig. 2B). Oct4 was expressed at high levels in ES and EPL cell cultures as described previously (Rathjen et al., 1999), consistent with the expression of this gene in ICM and primitive ectoderm cells in vivo (Rosner et al., 1990; Scholer et al., 1990; Yeom et al., 1991). A $9.4 \mathrm{~kb} C R T R-1$ transcript was produced in ES and EPL cells cultured for 2 days in MEDII
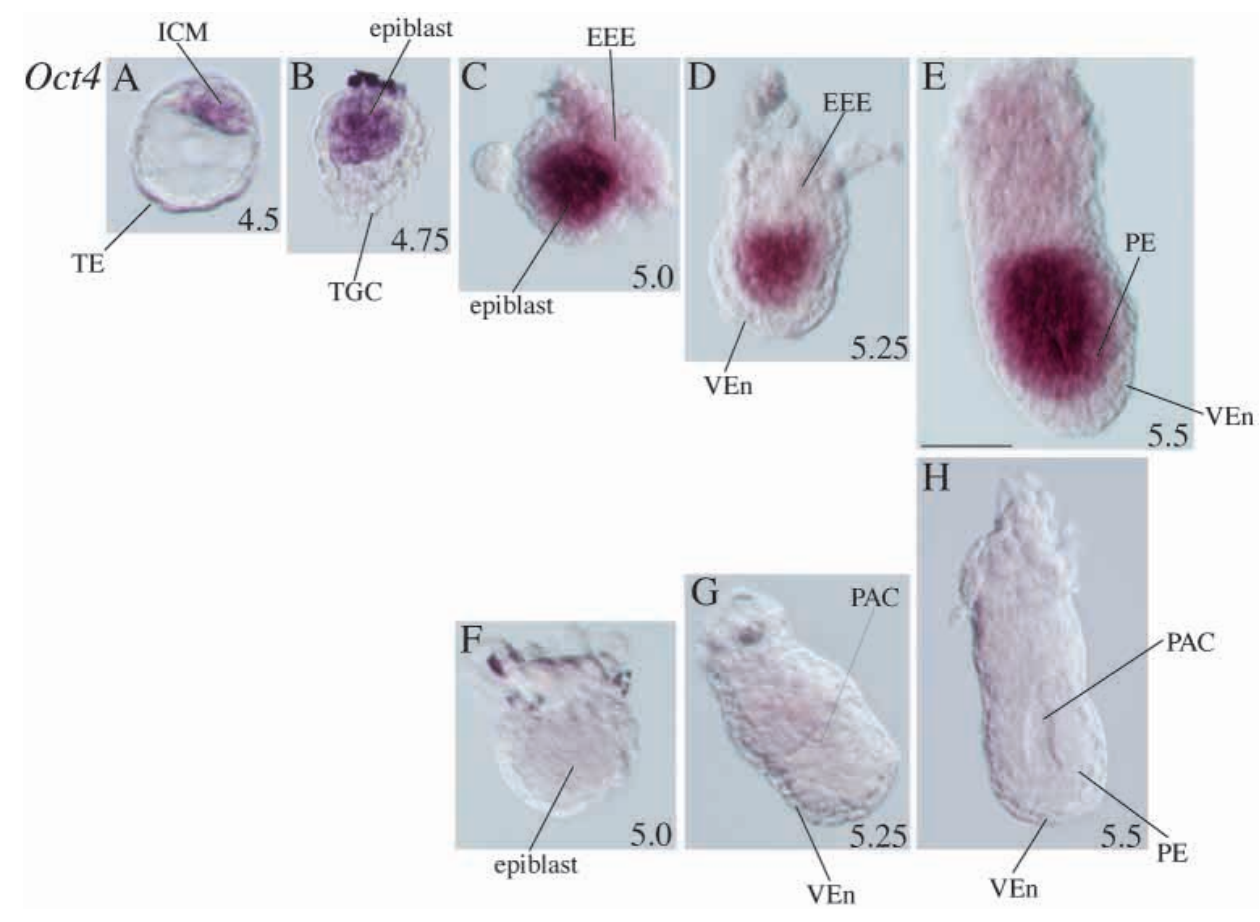

Fig. 4. Definition of embryonic stages and identification of pluripotent cell populations by analysis of Oct4 expression. Whole mount in situ hybridization analysis of 4.5 d.p.c. (A), 4.75 d.p.c. (B), 5.0 d.p.c. (C), 5.25 d.p.c. (D) and 5.5 d.p.c.

(E) mouse embryos using antisense digoxygenin-labelled Oct4 riboprobes. (F) A 5.0 d.p.c. embryo analysed by whole mount in situ hybridization using antisense digoxygenin-labelled $P R C E$ riboprobes. (G) A 5.25 d.p.c. embryo and $(\mathrm{H})$ a 5.5 d.p.c. embryo analysed by whole mount in situ hybridization using sense digoxygeninlabelled PRCE riboprobes. (F-H) These images are included to illustrate the formation of the proamniotic cavity (PAC) and pseudostratified epithelial layer of primitive ectoderm (PE). Abbreviations: EEE, extra-embryonic ectoderm; ICM, inner cell mass; TE, trophectoderm; TGC, trophoblast giant cells; VEn, visceral endoderm. Bar, $50 \mu \mathrm{m}$. The colouration in the trophectoderm of the 4.5 d.p.c. blastocyst is not cellular but can be attributed to a shadow rather than gene expression. 


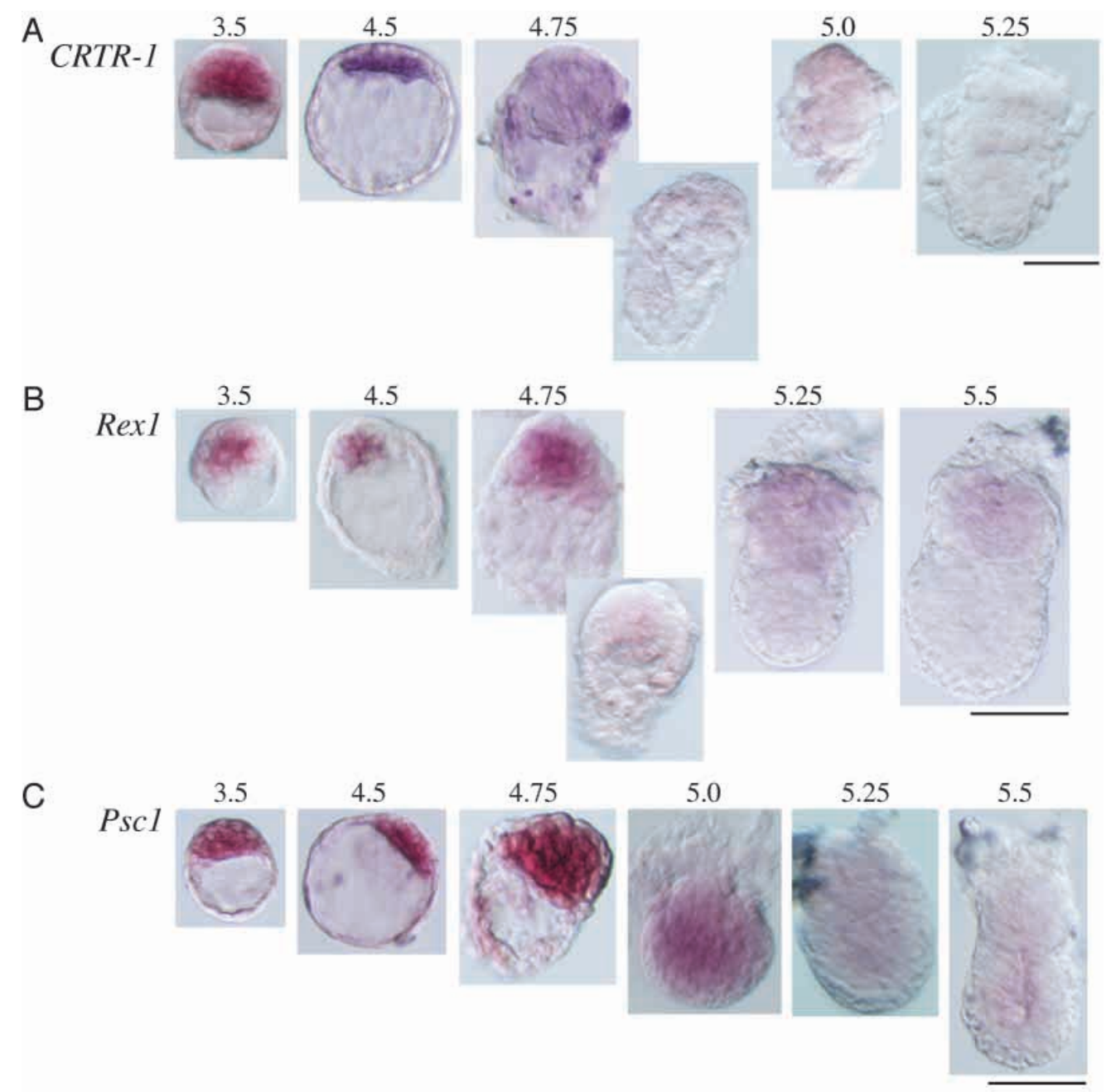

Fig. 5. Expression of CRTR-1, Rexl and Pscl during early mouse embryogenesis. Analysis of CRTR-1 (A), Rexl (B) and Pscl (C) expression by whole mount in situ hybridization of 3.5-5.5 d.p.c. mouse embryos using antisense digoxygenin-labelled riboprobes. Bar, $50 \mu \mathrm{m}$. Display of two embryos at a given time point indicates inconsistent expression, interpreted as marking the time of downregulation. or 2 and 4 days in MEDII + LIF, and was downregulated with EPL cell culture to undetectable levels after culture for 4 days in the absence of LIF or 6 days in the presence of LIF. Rexl was also expressed at highest levels in ES cells and downregulated during EPL cell culture, with kinetics indistinguishable from those of CRTR-1. A $5.5 \mathrm{~kb} P s c 1$ transcript was detected in ES and EPL cells cultured for 2 days in the absence of LIF, or for 2 and 4 days in the presence of LIF. In comparison with both $C R T R-1$ and Rex 1 , expression of this gene persisted longer in EPL cells, with low but detectable levels of expression in EPL cells cultured for 4 days in the absence of LIF and downregulation to very low levels only being observed on day 6 in both the presence and absence of LIF. Fgf5 expression could not be detected in ES cells but was upregulated in EPL cells cultured for 4 days in the presence and 2 days in the absence of LIF, with a further increase in expression after culture of EPL cells for 6 and 4 days, respectively. A $6.6 \mathrm{~kb} P R C E$ transcript was detected in ES and EPL cells. Expression was upregulated upon formation of EPL cells, with a peak of expression 1.7 times that seen in ES cells seen after culture for 4 days in 50\% MEDII + LIF (Fig. 2B). Further culture in $50 \%$ MEDII + LIF resulted in a downregulation of PRCE expression. In situ hybridization of ES and EPL cells with antisense digoxygenin-labelled probes specific for PRCE and Oct4 confirmed the upregulation of
PRCE expression between ES and EPL cells cultured for 2 days (Fig. 2C).

Different expression of pluripotent cell markers during the ES-EPL cell transition was consistent with previous results (Rathjen et al., 1999) and with the patterns predicted by ddPCR analysis. Temporally distinct populations of pluripotent cells subdividing the $\mathrm{Oct}_{4}{ }^{+}$population could be identified during the differentiation of ES to EPL cells by the expression of different combinations of genes.

ES and EPL cell cultures can be contaminated by low levels of differentiated cells (Rathjen et al., 1999), generally located at the periphery of colonies. Expression of CRTR-1, Pscl and $P R C E$ was shown to be associated with pluripotent cells by in situ hybridization to ES and EPL cell monolayers in vitro using antisense digoxygenin-labelled probes. Expression of these genes was associated with most cells in the culture, located centrally within colonies and exhibiting a pluripotent cell morphology (Rathjen et al., 1999). Sporadic differentiated cells within the cultures did not express CRTR-1, Pscl or PRCE (Fig. 2D; data not shown).

\section{Sequence of cDNAs}

The CRTR-1, Pscl and PRCE cDNA fragments in pBluescript were sequenced in both directions, revealing sizes of $736 \mathrm{bp}$, 

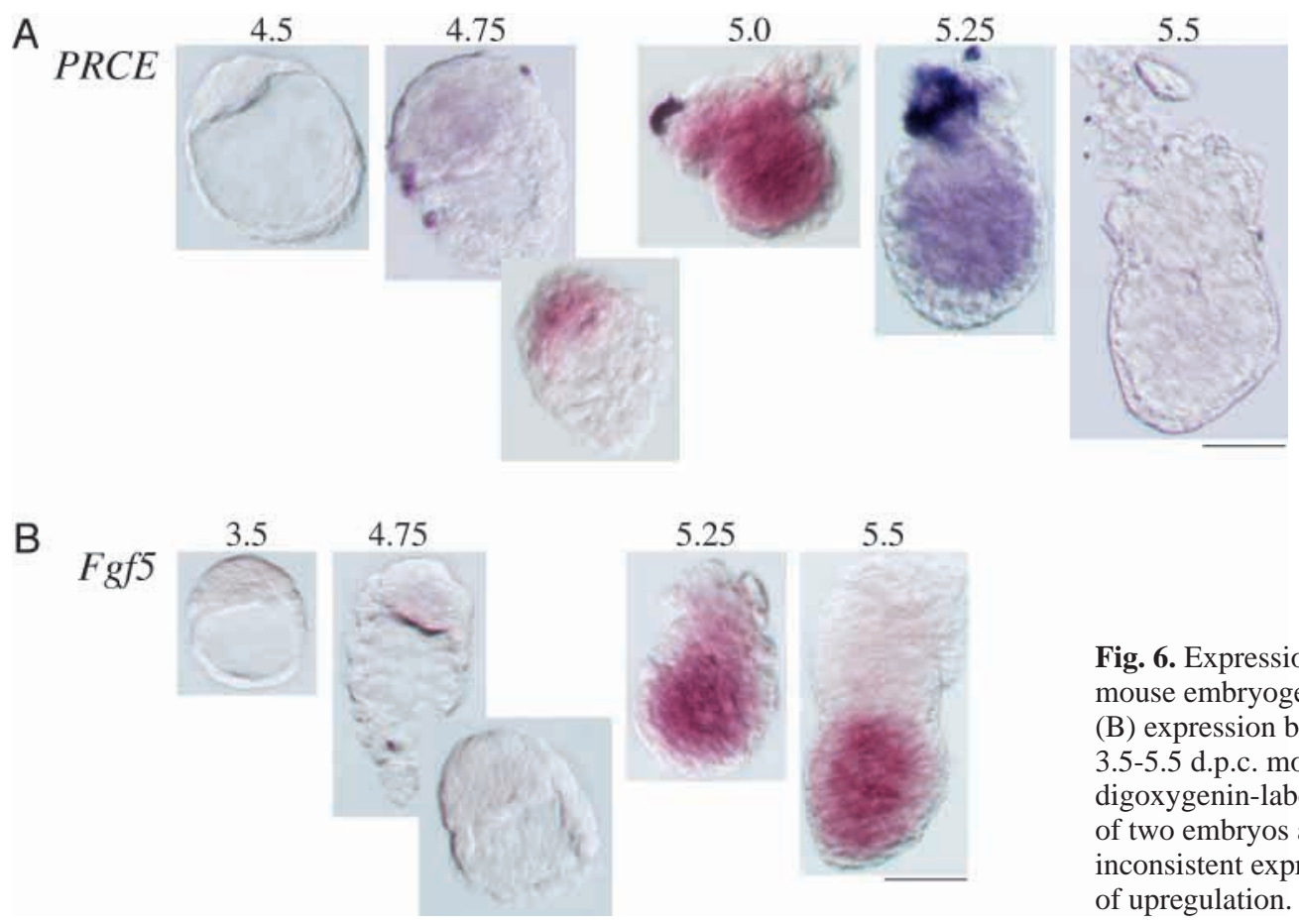

\begin{abstract}
Fig. 6. Expression of $P R C E$ and $F g f 5$ during early mouse embryogenesis Analysis of PRCE (A) and Fgf5 (B) expression by whole mount in situ hybridization of 3.5-5.5 d.p.c. mouse embryos using antisense digoxygenin-labelled riboprobes. Bar, $50 \mu \mathrm{m}$. Display of two embryos at a given time point indicates inconsistent expression, interpreted as marking the time of upregulation.
\end{abstract}

$458 \mathrm{bp}$ and $232 \mathrm{bp}$, respectively. The CRTR-1 and PRCE cDNAs were isolated using a 3'-anchored-oligo (dT) primer and potentially represent $3^{\prime}$ UTR sequence in these large transcripts. Further analysis of CRTR-1 cDNA and the biochemical properties of CRTR-1 has revealed homology to the CP2 family of transcription factors (Rodda et al., 2001) (accession number AF311309). Analysis of PRCE revealed $71.3 \%$ identity with the human cDNA KIAA0165 (Fig. 3A), isolated from the immature myeloid cell line KG-1 (Nagase et al., 1996). Additional sequence data and analysis suggest functional equivalence with fungal separins and a role in chromosome segregation (T. A. Pelton, PhD thesis, Adelaide University, 2000). The Pscl cDNA fragment, which was isolated by idPCR, contained an uninterrupted open reading frame with a region homologous (44.8\% identity) to the predicted CELB0336.3 open reading frame from Caenorhabditis elegans (Wilson et al., 1994) (accession number U32305; Fig. 3B). Sequence homologies and immunocytochemical analysis of protein localization in transfected cells indicate that Pscl is a member of the SR protein family with a role in RNA metabolism (S. J. Kavanagh, Honours thesis, Adelaide University, 1998).

\section{Expression of genes in pluripotent cell populations in vivo}

\section{Stage definition and Oct4 expression}

The predicted range of expression of marker genes used in this analysis is defined by the ES-EPL cell transition and encompasses the pluripotent cells of the blastocyst ICM (3.5 d.p.c.) to the primitive ectoderm of the egg cylinder at 5.5 d.p.c. (Rathjen et al., 1999). The timing of these stages of development vary between mouse strains and individual embryos within a litter show some heterogeneity in developmental progression. Accordingly, the stages of embryogenesis were defined by morphological criteria. Representative staged embryos between 4.5 d.p.c. and 5.5 d.p.c. stained for the pluripotent cell marker Oct4 are presented in Fig. 4 to illustrate the embryonic cell populations.

The 3.5 d.p.c. blastocyst has an ICM partitioned to one end of the blastocoelic cavity but no evidence of primitive endoderm. Later blastocysts (4.0 d.p.c.) were identified by the presence of a primitive endoderm layer. Embryos at 4.5 d.p.c. (expanded blastocyst; Fig. 4A) had hatched from the zona pellucida and assumed an enlarged, ovoid morphology containing a compacted pluripotent cell population. Late-stage blastocysts (4.75 d.p.c.; Fig. 4B) were identified by two criteria: formation of migratory primary trophoblast giant cells and an expanded epiblast population. Embryos at 5.0 d.p.c. were characterized by the displacement of pluripotent cells to fill the blastocoelic cavity, resulting in loss of a discernible cavity (Fig. 4C). Formation of a proamniotic cavity within the pluripotent cells was used to identify embryos later than 5.0 d.p.c. Cavity formation is first evident at 5.25 d.p.c. (Fig. 4D) and is followed by polarization and reorganization of the pluripotent cells into a pseudostratified epithelial sheet of primitive ectoderm by 5.5 d.p.c. (Fig. 4E). Post-proamniotic cavity embryos were also staged on the size of the proamniotic cavity and arrangement of the pluripotent cells. As reported previously (Rosner et al., 1990; Scholer et al., 1990; Yeom et al., 1991), Oct4 transcripts were not detected at any of these stages in trophectodermal derivatives or derivatives of the primitive endoderm.

In vivo expression of PSC1, CRTR-1, PRCE, Rex1 and Fgf5

Flushed pre- and early post-implantation embryos (to $\sim 4.75$ d.p.c.) or dissected post-implantation embryos were examined for gene expression by whole mount in situ hybridization. 
To allow detailed mapping of expression during this experimentally difficult period, embryos were isolated at $\sim 0.25$ d.p.c. intervals.

CRTR-1 expression (Fig. 5A) was detected uniformly in pluripotent cells of the 3.5 d.p.c. embryo and 4.5 d.p.c. expanded blastocyst. Expression was inconsistent and at low levels in 4.75 d.p.c. embryos, suggesting downregulation of the gene at this time. CRTR-1 transcripts were not detected in pluripotent cell populations of the 5.0 d.p.c. or 5.25 d.p.c. embryo, or in extra-embryonic cell types from the trophectodermal or primitive endoderm lineages at any of the stages analysed.

Consistent with their jointly regulated expression in vitro, the expression pattern of Rexl in pluripotent cells in vivo was equivalent to that of $C R T R-1$. Rexl expression was detected in all pluripotent cells at 3.5 d.p.c., extending the findings of Rogers et al. (Rogers et al., 1991) who demonstrated expression at 4.5 d.p.c. Rexl expression persisted within all pluripotent cells at 4.5 d.p.c. but was downregulated at $\sim 4.75$ d.p.c. and was not detected subsequently in pluripotent cells of the embryo (Fig. 5B). Rexl expression was not observed in trophectoderm or primitive endoderm derived extra-embryonic lineages up to 4.75 d.p.c., but this gene was subsequently expressed at low levels in the extra-embryonic ectoderm following proamniotic cavitation at 5.25 d.p.c. This expression presumably persists until 6.0 d.p.c., as described previously (Rogers et al., 1991).

Pscl was found to be expressed within the pluripotent cell pool in a pattern overlapping but distinct from those of CRTR1 and Rexl (Fig. 5C). Early embryonic expression was observed in all pluripotent cells but not trophectodermal cells of the 3.5 d.p.c. blastocyst and was maintained in the compacted epiblast of the expanded blastocyst at 4.5 d.p.c. In contrast to CRTR-1 and Rexl, Pscl transcripts were detected uniformly throughout cells of the epiblast at 4.75 d.p.c. and at lower, variable levels in pluripotent cells at 5.0 d.p.c., immediately prior to proamniotic cavity formation. Expression was downregulated in pluripotent cells immediately following the earliest morphological evidence of proamniotic cavitation, a later stage than downregulation of $C R T R-1$ and Rex 1 , and was not observed in later stage embryos that contained larger proamniotic cavities. Pscl expression was not detected in primitive endoderm or other extra-embryonic cell types.

Expression of PRCE was not detected by whole mount in situ hybridization in 3.5 d.p.c. (not shown) and 4.5 d.p.c. embryos (Fig. 6A). Low level expression was first detected throughout the pluripotent cell pool at 4.75 d.p.c. and higher levels of expression were apparent in pluripotent cells of 5.0 d.p.c. embryos. PRCE expression persisted within pluripotent cells at 5.25 d.p.c., after formation of the proamniotic cavity. Expression in the extra-embryonic ectoderm at 5.25 d.p.c. was also noted. PRCE expression was not detected following polarization and reorganization of primitive ectoderm into a columnar epithelial sheet at 5.5-5.75 d.p.c.

Although Fgf5 has been shown to be expressed in pluripotent cells of the primitive ectoderm at 5.25 d.p.c. but not ICM cells at 3.5 d.p.c. (Haub and Goldfarb, 1991; Hebert et al., 1991), the timing of upregulation has not been mapped closely. In this study, Fgf5 expression was not detected in the pluripotent cell populations of the embryo up to 4.75 d.p.c., although an unexpected observation was the detection of $\mathrm{Fgf5}$ expression in primitive endoderm at 4.75 d.p.c. (Fig. 6B) in 8 of the 21 embryos analysed. Expression of $F g f 5$ in pluripotent cells was observed throughout the population following the initiation of proamniotic cavitation at 5.25-5.5 d.p.c., but not in extra-embryonic tissues at this stage. Expression of Fgf5 continues in the primitive ectoderm until the onset of gastrulation (not shown) (Haub and Goldfarb, 1991; Hebert et al., 1991).

\section{Discussion \\ Gene expression analysis reveals temporally distinct pluripotent cell subpopulations}

Oct4 was expressed in all pluripotent cell populations examined, consistent with previous results in vitro and in vivo (Rosner et al., 1990; Scholer et al., 1990; Yeom et al., 1991; Rathjen et al., 1999), and the apparent requirement for this transcription factor in pluripotent cell maintenance (Nichols et al., 1998). Within the Oct4 ${ }^{+}$pool, however, progressive but distinct pluripotent cell gene expression patterns could be identified. Cells of the 3.5 d.p.c. and 4.5 d.p.c. blastocyst and ES cells (in vitro) expressed Oct4, CRTR-1, Rexl and Psc1, but not Fgf5. Although PRCE was expressed at low levels in the ES cell population, no expression was detected in the ICM population of the embryo. Downregulation of CRTR- 1 and Rexl at $\sim 4.75$ d.p.c. provided molecular evidence for transition of the pluripotent cell population. This transition was accompanied by maintenance of Oct4 and Pscl expression, and initiation of PRCE expression. Interestingly, this stage of embryogenesis was also characterized by upregulation of $F g f 5$ expression in extra-embryonic endoderm.

Expression of Pscl in the absence of CRTR-1 and Rexl identified a subsequent pluripotent cell population present between 4.75 d.p.c. and the onset of proamniotic cavitation. Downregulation of $P s c l$ expression between 5.0 d.p.c. and 5.25 d.p.c., and expression of $F g f 5$ resulted in a population of pluripotent cells that expressed $O c t 4, P R C E$ and $F g f 5$, and was succeeded, following downregulation of $P R C E$ expression between 5.25 d.p.c. and 5.5 d.p.c., by a pluripotent cell population expressing $\mathrm{Oct} 4$ and $\mathrm{Fgf5}$. This expression pattern is maintained in pluripotent cells until gastrulation (Haub and Goldfarb, 1991; Yeom et al., 1991).

The existence of temporal intermediate pluripotent cell populations in vivo, which differ from preceding and following pluripotent cell populations, can therefore be demonstrated by different gene expression. This is perhaps best illustrated by the expression of $P R C E$, which was expressed in pluripotent cells in a brief developmental window between 4.75 d.p.c. and 5.25 d.p.c. Whereas pluripotent cell populations exhibited the anticipated temporal heterogeneity in gene expression, no evidence was obtained for spatial heterogeneity within the pluripotent cell pool. This is consistent with the demonstration that spatially distinct pluripotent cells in 5.5 d.p.c. and 6.5 d.p.c. embryos are not committed to alternate developmental fates (Beddington, 1981; Beddington, 1982; Beddington, 1983b; Lawson et al., 1991).

\section{Alterations in pluripotent cell gene expression correlate with developmental events}

The delineation of temporally distinct pluripotent cell 
populations in vivo points to a gradual transition between the ICM and primitive ectoderm. This stage of mouse embryogenesis is characterized by morphologically identifiable developmental events that correlate closely with the alterations in gene expression. A major change in pluripotent cell gene expression was mapped at $\sim 4.75$ d.p.c., when CRTR-1 and Rexl were downregulated, apparently simultaneously, and PRCE expression was initiated. This coincides with an embryological transition from slow cell division within the oviduct with no overall increase in embryo size to a rapid increase in the growth rate of the embryo, particularly within the pluripotent cells between 4.5 d.p.c. and 5.5 d.p.c. (Snow, 1977; Hogan et al., 1994). A number of null mutant embryos, including Fgf4 (Feldman et al., 1995), Fgfr2 (Armand et al., 1998), Brcal (Hakem et al., 1996; Liu et al., 1996; Ludwig et al., 1997), $\beta 1$ integrin (Fassler and Meyer, 1995; Stephens et al., 1995) and EGFR (Threadgill et al., 1995), degenerate following implantation as a result of impaired pluripotent cell proliferation. Different phenotypes suggest the involvement of several signalling pathways at this time. Alterations in Rex $1, C R T R-1$ and PRCE expression may be responsive to extracellular signals regulating this phase of peri-implantation pluripotent cell development, such as members of the FGF family (Feldmen et al., 1995; Armand et al., 1998). The unexpected expression of $F g f 5$ in primitive endoderm at 4.75 d.p.c., as reported in this work, provides a potential source of these signals, consistent with a hypothesized instructive role for this extra-embryonic cell type in the blastocyst (Thomas et al., 1998).

In similar manner, downregulation of Pscl expression coincided with formation of the proamniotic cavity, a process thought to be regulated by the combined action of a diffusible 'death' signal secreted by visceral endoderm and a matrixassociated 'survival' signal (Coucouvanis and Martin, 1995) and downregulation of PRCE expression correlated with reorganization of pluripotent cells into a sheet of pseudostratified epithelium in vivo. Transcriptional analysis of differently expressed pluripotent cell markers may therefore provide a means for identification of the cellular origin and timing of important embryonic signals.

\section{Identification of pluripotent cell populations in vitro}

Gene expression specific for ES cells, as assessed by expression of Oct4, CRTR-1, Rexl and Pscl, and lack of Fgf5, was consistent with gene expression in pluripotent cells in vivo between 3.5 d.p.c. and 4.75 d.p.c. Although early results have commonly been interpreted as suggesting an embryonic origin for ES cells in pre-implantation embryos, it has recently been demonstrated that ES cell lines can be isolated from periimplantation embryos with greater efficiency (Brook and Gardner, 1997). Although our results are consistent with either an early or a late embryonic equivalent to ES cells, the gene expression pattern described in this work provides a latest time point for the embryonic equivalent at $\sim 4.5$ d.p.c. This is consistent with the demonstration that pluripotent cells from post-implantation embryos do not contribute to chimaeras following blastocyst injection (Beddington, 1983a). Expression of genes such as Rexl and CRTR-1, if conserved across species, could provide superior markers for the identification of ES cell equivalents in the embryos of diverse species.
Although expression of the $P R C E$ gene was tightly regulated in vivo, $P R C E$ expression in vitro appeared to be less tightly regulated with low level expression detected in ES cells by ddPCR, northern blot and in situ hybridization. Co-expression in ES cells of Rex 1 and CRTR-1 with PRCE is inconsistent with our descriptions of pluripotent cells in vivo and may be associated with the rapid proliferation exhibited by ES cells in culture and pluripotent cells of the peri-implantation embryo or simply reflect deregulated gene expression associated with growth in vitro.

Although there is some variability in the rate of ES-EPL cell transition, the temporal regulation of gene expression described in pluripotent cells in vivo was recapitulated in this in vitro system, supporting our previous identification of late EPL cells as representative of early primitive ectoderm (Rathjen et al., 1999). EPL cells cultured for 4 days in the presence of LIF or 2 days in the absence of LIF demonstrated a gene expression pattern analogous to pluripotent cells of the 4.75 d.p.c. embryo in which expression of $C R T R-1$ and Rexl was reduced and PRCE increased. EPL cells cultured for 4 days in the absence or 6 days in the presence of LIF shared gene expression with pluripotent cells of the 4.75-5.0 d.p.c. embryo, which express Pscl and PRCE but not CRTR-1 or Rex 1. EPL cells cultured for 6 days in the absence of LIF demonstrated downregulated $P s c l$ expression but retained high level expression of $F g f 5$ and therefore expressed a repertoire of genes analogous to primitive ectoderm populations occurring 5.25 d.p.c. Downregulation of PRCE expression was slow in vitro, in contrast to the tight regulation of this gene between 4.75 d.p.c. and 5.25 d.p.c. in vivo. This may reflect the lack in vitro of three-dimensional architecture required for epithelialization. In general, the developmental progression in vitro was significantly slower than that observed in vivo. This is common to many cell culture systems and presumably reflects absence of an optimal environment for developmental progression in vitro.

Analysis of genes expressed differently between ES and EPL cells therefore allowed the definitive identification of previously unidentified pluripotent cell populations. These populations may share properties with some of the diverse pluripotent cell lines that have been isolated from non-mouse mammalian species (Thomson et al., 1998; Reubinoff et al., 2000) and non-ICM pluripotent cell sources (Pera, 1990; Resnick et al., 1992; Matsui et al., 1992; Shamblott et al., 1998). Molecular characterization of these populations with Psc1, CRTR-1 and PRCE allowed a close alignment of in vivo populations and EPL cells, and demonstrated that, after 6-8 days in culture, EPL cells share a gene expression profile with 5.25 d.p.c. primitive ectoderm. EPL cells cultured for less than 6-8 days could be aligned with temporal pluripotent intermediates formed in the embryo between 4.5 d.p.c. and 5.25 d.p.c. The ability to generate a homogeneous population in culture equivalent to primitive ectoderm provides a substrate for the development of model systems for the investigation of pluripotent cell differentiation, and may provide a starting point for the development of procedures for directed cell differentiation and production of cell populations with therapeutic applications from pluripotent cells.

We would like to thank J. Nichols and A. Smith (Centre for Genome Research, Edinburgh, UK) for early lessons in embryonic dissection 
and DEET for supporting transfer of these techniques from Edinburgh to Adelaide. This work was supported by grants from the Australian Research Council and BresaGen.

\section{REFERENCES}

Armand, E., Haffner-Krausz, R., Chen, Y., Heath, J. K. and Lonai, P. (1998). Targeted disruption of fibroblast growth factor (FGF) receptor 2 suggests a role for FGF signaling in pregastrulation mammalian development. Proc. Natl. Acad. Sci. USA 95, 5082-5087.

Beddington, S. P. (1981). An autoradiographic analysis of the potency of embryonic ectoderm in the 8th day postimplantation mouse embryo. $J$. Embryol. Exp. Morphol. 64, 87-104.

Beddington, R. S. (1982). An autoradiographic analysis of tissue potency in different regions of the embryonic ectoderm during gastrulation in the mouse. J. Embryol. Exp. Morphol. 69, 265-285.

Beddington, R. S. (1983a). Histogenetic and neoplastic potential of different regions of the mouse embryonic egg cylinder. J. Embryol. Exp. Morphol. 75, 189-204.

Beddington, R. S. P. (1983b). The origin of foetal tissues during gastrulation in the rodent. In Development in Mammals (ed. M. H. Johnson), pp. 1-32. Amsterdam: Elsevier.

Brook, F. A. and Gardner, R. L. (1997). The origin and efficient derivation of embryonic stem cells in the mouse. Proc. Natl. Acad. Sci. USA 94, 57095712.

Celano, P., Vertino, P. M. and Casero, R. A., Jr (1993). Isolation of polyadenylated RNA from cultured cells and intact tissue. BioTechniques 15, 27-28.

Chapman, G., Remiszewski, J. L., Webb, G. C., Schulz, T. C., Bottema, C. D. and Rathjen, P. D. (1997). The mouse homeobox gene, Gbx2: genomic organization and expression in pluripotent cells in vitro and in vivo. Genomics 46, 223-233.

Coucouvanis, E. and Martin, G. R. (1995). Signals for death and survival: a two-step mechanism for cavitation in the vertebrate embryo. Cell 83, 279287.

Deng, C. X., Wynshaw-Boris, A., Shen, M. M., Daugherty, C., Ornitz, D. M. and Leder, P. (1994). Murine FGFR-1 is required for early postimplantation growth and axial organization. Genes Dev. 8, 3045-3057.

Doetschman, T. C., Eistetter, H., Katz, M., Schmidt, W. and Kemler, R. (1985). The in vitro development of blastocyst-derived embryonic stem cell lines: formation of visceral yolk sac, blood islands and myocardium. $J$. Embryol. Exp. Morphol. 87, 27-45.

Edwards, D. R., Parfett, C. L. and Denhardt, D. T. (1985). Transcriptional regulation of two serum-induced RNAs in mouse fibroblasts: equivalence of one species to B2 repetitive elements. Mol. Cell Biol. 5, 3280-3288.

Evans, M. J. and Kaufman, M. H. (1981). Establishment in culture of pluripotential cells from mouse embryos. Nature 292, 154-156.

Fassler, R. and Meyer, M. (1995). Consequences of lack of beta 1 integrin gene expression in mice. Genes Dev. 9, 1896-1908.

Feldman, B., Poueymirou, W., Papaioannou, V. E., DeChiara, T. M. and Goldfarb, M. (1995). Requirement of FGF-4 for postimplantation mouse development. Science 267, 246-249.

Hakem, R., de la Pompa, J. L., Sirard, C., Mo, R., Woo, M., Hakem, A., Wakeham, A., Potter, J., Reitmair, A., Billia, F. et al. (1996). The tumor suppressor gene Brcal is required for embryonic cellular proliferation in the mouse. Cell 85, 1009-1023.

Haub, O. and Goldfarb, M. (1991). Expression of the fibroblast growth factor-5 gene in the mouse embryo. Development 112, 397-406.

Hebert, J. M., Boyle, M. and Martin, G. R. (1991). mRNA localization studies suggest that murine FGF-5 plays a role in gastrulation. Development 112, 407-415

Hogan, B., Beddington, R., Constantini, F. and Lacy, E. (1994). Manipulating the Mouse Embryo. Cold Spring Harbor: Laboratory Press.

Hosler, B. A., LaRosa, G. J., Grippo. J. F. and Gudas, L. (1989). Expression of Rex-1, a gene containing zinc finger motifs, is rapidly reduced by retinoic acid in F9 teratocarcinoma cells. Mol. Cell. Biol. 9, 5623-5629.

Kaufman, M. H. (1992). The Atlas of Mouse Development. London: Academic Press.

Lake, J., Rathjen, J., Remiszewski, J. and Rathjen, P. D. (2000). Reversible programming of pluripotent cell differentiation. J. Cell Sci. 113, 555-566.

Lawson, K. A., Meneses, J. J. and Pedersen, R. A. (1991). Clonal analysis of epiblast fate during germ layer formation in the mouse embryo. Development 113, 891-911.
Liang, P. and Pardee, A. B. (1992). Differential display of eukaryotic messenger RNA by means of the polymerase chain reaction. Science 257, 967-971.

Liu, C. Y., Flesken-Nikitin, A., Li, S., Zeng, Y. and Lee, W. H. (1996). Inactivation of the mouse Brcal gene leads to failure in the morphogenesis of the egg cylinder in early postimplantation development. Genes Dev. 10, $1835-1843$.

Ludwig, T., Chapman, D. L., Papaioannou, V. E. and Efstratiadis, A. (1997). Targeted mutations of breast cancer susceptibility gene homologs in mice: lethal phenotypes of Brca1, Brca2, Brcal/Brca2, Brcal/p53 and Brca2/p53 nullizygous embryos. Genes Dev. 11, 1226-1241.

Martin, G. R. (1981). Isolation of a pluripotent cell line from early mouse embryos cultured in medium conditioned by teratocarcinoma stem cells. Proc. Natl. Acad. Sci. USA 78, 7634-7638.

Matsui, Y., Zsebo, K. and Hogan, B. L. (1992). Derivation of pluripotential embryonic stem cells from murine primordial germ cells in culture. Cell 70, 841-847.

Nagase, T., Seki, N., Ishikawa, K., Ohira, M., Kawarabayasi, Y., Ohara, O., Tanaka, A., Kotani, H., Miyajima, N. and Nomura, N. (1996). Prediction of the coding sequences of unidentified human genes. VI. The coding sequences of 80 new genes (KIAA0201-KIAA0280) deduced by analysis of cDNA clones from cell line KG-1 and brain. DNA Res. 3, 321329, 341-354.

Nichols, J., Zevnik, B., Anastassiadis, K., Niwa, H., Klewe Nebenius, D., Chambers, I., Scholer, H. and Smith, A. (1998). Formation of pluripotent stem cells in the mammalian embryo depends on the POU transcription factor Oct4. Cell 95, 379-391.

Pease, S., Braghetta, P., Gearing, D., Grail, D. and Williams, R. L. (1990). Isolation of embryonic stem (ES) cells in media supplemented with recombinant leukemia inhibitory factor (LIF). Dev. Biol. 141, 344-352.

Pelton, T. A., Bettess, M. D., Lake, J., Rathjen, J. and Rathjen, P. D. (1998) Developmental complexity of early mammalian pluripotent cell populations in vivo and in vitro. Reprod. Fertil. Dev. 10, 535-549.

Pera, M. F., Roach, S. and Elliss, C. J. (1990). Comparative biology of mouse and human embryonal carcinoma. Cancer Surv. 9, 243-262.

Rathjen, P. D., Toth, S., Willis, A., Heath, J. K. and Smith, A. G. (1990). Differentiation inhibiting activity is produced in matrix-associated and diffusible forms that are generated by alternate promoter usage. Cell $\mathbf{6 2}$, 1105-1114.

Rathjen, P. D., Lake, J., Whyatt, L. M., Bettess, M. D. and Rathjen, J. (1998). Properties and uses of embryonic stem cells: prospects for application to human biology and gene therapy. Reprod. Fertil. Dev. 10, 3147.

Rathjen, J., Lake, J. A., Bettess, M. D., Washington, J. M., Chapman, G. and Rathjen, P. D. (1999). Formation of a primitive ectoderm like cell population, EPL cells, from ES cells in response to biologically derived factors. J. Cell Sci. 112, 601-612.

Resnick, J. L., Bixler, L. S., Cheng, L. and Donovan, P. J. (1992). Longterm proliferation of mouse primordial germ cells in culture. Nature $\mathbf{3 5 9}$, 550-551.

Reubinoff, B. E., Pera, M. F., Fong, C. Y., Trounson, A. and Bongso, A. (2000). Embryonic stem cell lines from human blastocysts: somatic differentiation in vitro. Nat. Biotechnol. 18, 399-404.

Rodda, S., Sharma, S., Scherer, M., Chapman, G. and Rathjen, P. (2001). CRTR-1, a developmentally regulated transcriptional repressor related to the CP2 family of transcription factors. J. Biol. Chem. 276, 3324-3332.

Rogers, M. B., Hosler, B. A. and Gudas, L. J. (1991). Specific expression of a retinoic acid-regulated, zinc-finger gene, Rex-1, in preimplantation embryos, trophoblast and spermatocytes. Development 113, 815-824.

Rosen, B. and Beddington, R. S. (1993). Whole-mount in situ hybridization in the mouse embryo: gene expression in three dimensions. Trends Genet. 9, 162-167.

Rosner, M. H., Vigano, M. A., Ozato, K., Timmons, P. M., Poirier, F., Rigby, P. W. and Staudt, L. M. (1990). A POU-domain transcription factor in early stem cells and germ cells of the mammalian embryo. Nature 345, 686-692.

Scholer, H. R., Ruppert, S., Suzuki, N., Chowdhury, K. and Gruss, P. (1990). New type of POU domain in germ line-specific protein Oct-4. Nature 344, 435-439.

Shamblott, M. J., Axelman, J., Wang, S., Bugg, E. M., Littlefield, J. W., Donovan, P. J., Blumenthal, P. D., Huggins, G. R. and Gearhart, J. D. (1998). Derivation of pluripotent stem cells from cultured human primordial germ cells. Proc. Natl. Acad. Sci. USA 95, 13726-13731. 
Shen, M. M. and Leder, P. (1992). Leukemia inhibitory factor is expressed by the preimplantation uterus and selectively blocks primitive ectoderm formation in vitro. Proc. Natl. Acad. Sci. USA 89, 8240-8244.

Smith, A. G. (1992). Mouse embryo stem cells: their identification, propagation and manipulation. Semin. Cell Biol. 3, 385-399.

Smith, A. (1998). Cell therapy: in search of pluripotency. Curr. Biol. 8, R802R804.

Snow, M. H. L. (1977). Gastrulation in the mouse: growth and regionalization of the epiblast. J. Embryol. Exp. Morphol. 42, 293-303.

Spyropoulos, D. D. and Capecchi, M. R. (1994). Targeted disruption of the even-skipped gene, evxl, causes early postimplantation lethality of the mouse conceptus. Genes Dev. 8, 1949-1961.

Stephens, L. E., Sutherland, A. E., Klimanskaya, I. V., Andrieux, A., Meneses, J., Pedersen, R. A. and Damsky, C. H. (1995). Deletion of beta 1 integrins in mice results in inner cell mass failure and peri-implantation lethality. Genes Dev. 9, 1883-1895.

Thomas, P. Q., Johnson, B. V., Rathjen, J. and Rathjen, P. D. (1995). Sequence, genomic organization and expression of the novel homeobox gene Hesx1. J. Biol. Chem. 270, 3869-3875.

Thomas, P. Q., Brown, A. and Beddington, R. S. (1998). Hex: a homeobox gene revealing peri-implantation asymmetry in the mouse embryo and an early transient marker of endothelial cell precursors. Development 125, 8594.

Thomson, J. A., Itskovitz Eldor, J., Shapiro, S. S., Waknitz, M. A., Swiergiel, J. J., Marshall, V. S. and Jones, J. M. (1998). Embryonic stem cell lines derived from human blastocysts. Science 282, 1145-1147.

Threadgill, D. W., Dlugosz, A. A., Hansen, L. A., Tennenbaum, T., Lichti, U., Yee, D., LaMantia, C., Mourton, T., Herrup, K., Harris, R. C. et al. (1995). Targeted disruption of mouse EGF receptor: effect of genetic background on mutant phenotype. Science 269, 230-234.

Wilson, R., Ainscough, R., Anderson, K., Baynes, C., Berks, M., Bonfield, J., Burton, J., Connell, M., Copsey, T., Cooper, J. et al. (1994). $2.2 \mathrm{Mb}$ of contiguous nucleotide sequence from chromosome III of C. elegans. Nature 368, 32-38.

Yamaguchi, T. P., Harpal, K., Henkemeyer, M. and Rossant, J. (1994). fgfr1 is required for embryonic growth and mesodermal patterning during mouse gastrulation. Genes Dev. 8, 3032-3034

Yeom, Y. I., Ha, H. S., Balling, R., Scholer, H. R. and Artzt, K. (1991). Structure, expression and chromosomal location of the Oct-4 gene. Mech. Dev. 35, 171-179. 